\title{
Editorial
}

\section{The burden of glaucoma in Nepal}

\author{
Badhu B P \\ Department of Ophthalmology \\ BP Koirala Institute of Health Sciences \\ Dharan-18, Sunsari, Nepal
}

Considering the difficulty in detecting the disease in its early stage and the likelihood of irreversible loss of retinal nerve fibers at the time of diagnosis most of the time, glaucoma is an important public health problem. It is the third cause of blindness in Nepal after cataract and corneal conditions, according to the national survey of 1981 (Brilliant, 1985). The question of how big the magnitude of glaucoma blindness is in Nepal today requires an answer for effective planning of services to combat this problem.

A survey of published papers from Nepal on the glaucomas was done using the Medline database using the search words "glaucoma in Nepal" with the objective of describing the prevalence of glaucoma blindness in this country.

Knowledge of the prevalence of glaucoma and blindness due to it, awareness about the disease in the general population and effective tools to detect the disease amid the lack of resources are some of the important issues with respect to glaucoma as a public eye health problem. Some of the published research achievements have answered several questions concerning the glaucoma burden in Nepal. An estimated $3.2 \%$ of the total blindness in this country was reportedly due to glaucoma in 1981 . The awareness of glaucoma is $2.3 \%$ in the general population and is significantly lower in females as compared to their male counterparts, according to a population based study (Thapa et al, 2011). Though the finding of this study cannot be generalized for the whole country, it does provide a recognizable reflection of the seriousness of the condition. The most common glaucoma seen in the out-patient department of a hospital in south-east Nepal is primary angle-closure glaucoma (Sarkar et al, 2010). Lens-induced glaucoma is the commonest variant among the secondary glaucoma cases (Sarkar et al, 2010; Sah et al, 2007; Paudyal et al, 2011). According to a hospital-based study from a central hospital in Kathmandu, the glaucoma patients comprised of $0.74 \%$ of 110,794 outpatients (Rijal, 2005). Another hospital-based study from the south-east part of Nepal concluded that approximately $25 \%$ of the glaucoma patients were visually impaired or blind at the time of presentation (Sarkar et al, 2010). In another population-based study, the prevalence of glaucoma was found to be $0.938 \%$ and that of primary open-angle glaucoma (POAG), primary angleclosure glaucoma (PACG), secondary glaucoma and ocular hypertension was $0.562 \%, 0.125 \%, 0.250$ $\%$ and $0.5 \%$ respectively (Sah et al, 2007). More population-based studies with a uniform research design from various parts of the country are required for a more accurate estimation of the magnitude of the glaucoma burden in Nepal.

A positive aspect in the battle against the burden of gloucoma in Nepal is that there are more than 150 professionally-active ophthalmologists in the country and the number is increasing annually. Further more, the availability of a good number of well-trained ophthalmic paramedics and around 20 relatively well-

Address for correspondence: Dr Badri P Badhu, MD

Professor and Head

Department of Ophthalmology, BPKIHS, Dharan, Nepal

Phone No: +977-25-525555

E-mail: ophthalmology @ bpkihsacademics.edu.np 
equipped eye hospitals and approximately of the same number of eye departments of medical colleges in the country form a strong infra-structure to combat glaucoma blindness in Nepal. Glaucoma is detected and treated in these institutions. The available data suggest that the prevalence of POAG is higher than ACG in the community. Obviously, a large proportion of POAG remains undetected until it is too late for effective treatment and the prevention of blindness.

The situation at the community level, however, is alarming. This is particularly because of the low awareness of the disease among the general public and the poor attention given to glaucoma detection in community eye health programs. Thapa et al (2008) have reported that a simple, age-based glaucoma-screening algorithm incorporated into the cataract-screening community clinics is successful in detecting glaucoma and providing treatment.

In conclusion, the problem of glaucoma blindness in Nepal is challengingly high. We need to find out an effective method and incorporate it in practice to address this issue.

\section{References}

Brilliant LB, Pokharel RP, Grasset NC et al (1985). Epidemiology of blindness in Nepal. Bull WHO; 63: 375-86.

Paudyal I, Thapa SS, Paudyal G, Gurung R, Ruit S (2011). Glaucoma at a tertiary eye hospital in Nepal. Nepal J Ophthalmol; 3(6):123-127.

Sah RP, Badhu BP, Pokharel PK, Thakur SKD, Das H, Panda A (2007). Prevalence of glaucoma in Sunsari District of Eastern Nepal. Kathmandu Univ Med J; 5:343-8.

Sarkar S, Mardin C, Hennig A (2010). Profile of the glaucomas and interventions in a large eye care center in south-east Nepal. Nepal J ophthalmol; 2:3-9.

Thapa SS, Berg RV, Khanal S et al (2011). Prevalence of visual impairment, cataract surgery and awareness of cataract and glaucoma in Bhaktapur district of Nepal: the Bhaktapur Glaucoma Study. BMC Ophthalmol; 11:2.

Thapa SS, Kelley KH, Rens GV, Paudyal I, Chang L (2008). A novel approach to glaucoma screening and education in Nepal. BMC Ophthalmol; 11:2.

Rijal AP (2005). Clinical analysis of glaucoma in hospital patients. Kathmandu Univ Med J; 3(3):24954.

Source of support: nil. Conflict of interest: none 